\title{
Concurrent Onset of Chronic Lymphocytic Leukemia and Atypical Phenotype Acute Myeloid Leukemia Revealed by Autopsy
}

\author{
Sayaka Kiso ${ }^{a}$ Hiroyuki Sugiura $^{b}$ Taiga Kuroi $^{b}$ Rika Omote $^{c}$ \\ Tomohiro Toji $^{d}$ Tatsunori Ishikawab Sachiyo Okamotob ${ }^{b}$ Naho Nomura ${ }^{b}$ \\ Taro Masunarib $^{b}$ Nobuo Sezaki ${ }^{b}$ Toru Kiguchie ${ }^{\text {Mitsune Tanimoto }}{ }^{b}$

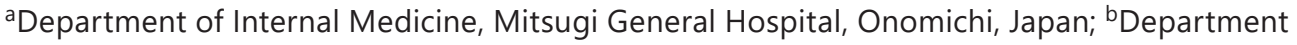 \\ of Hematology, Chugoku Central Hospital of Japan Mutual Aid Association of Public \\ School Teachers, Fukuyama, Japan; 'Department of Pathology, Chugoku Central Hospital \\ of Japan Mutual Aid Association of Public School Teachers, Fukuyama, Japan; dDepartment \\ of Pathology, Okayama University Hospital, Okayama, Japan; e'Department of Diabetes \\ Endocrinology and Hematology, Dokkyo Medical University Saitama Medical Center, \\ Koshigaya, Japan
}

\section{Keywords}

Chronic lymphocytic leukemia · Acute myeloid leukemia · Autopsy · Flow cytometry · Immunohistochemical staining

\begin{abstract}
The concurrent onset of chronic lymphocytic leukemia (CLL) and acute myeloid leukemia $(A M L)$ is rare, and no autopsy case has been reported. We report herein the first case of concurrent-onset CLL and AML with an atypical phenotype revealed by autopsy. Notably, the diagnosis of AML was quite difficult during the patient's lifetime because of the atypical phenotype. However, autopsy revealed that the patient's bone marrow, liver, and spleen were filled with myeloblasts. In addition, p53 stain and PCR of IgH rearrangement using the autopsy specimen suggested that CLL and AML might be different clones. In conclusion, our case highlights the importance of considering synchronous complications of AML in CLL patients, particularly in those with an atypical clinical course.
\end{abstract}




\section{Case Reports in Oncology}

\begin{tabular}{l|l}
\hline Case Rep Oncol 2021;14:1725-1732 \\
\hline DOI: 10.1159/000520427 & $\begin{array}{l}\text { @ 2021 The Author(s). Published by S. Karger AG, Basel } \\
\text { www.karger.com/cro }\end{array}$ \\
\hline
\end{tabular}

Kiso et al.: Autopsy Case of CLL and AML

\section{Introduction}

Myelodysplastic syndrome (MDS) or acute myeloid leukemia (AML) in patients with a previous diagnosis of chronic lymphocytic leukemia (CLL) is extremely rare, accounting for $<1 \%$ of cases [1]. The development of AML in patients with previously treated CLL is diagnosed as therapy-related AML, and it generally has inferior prognosis compared to that of de novo AML [2]. Although there have been reports of therapy-related AML, those on the development of AML in patients with untreated CLL are rare [3]. In the majority of synchronous cases of CLL and AML, flow cytometry and immunohistochemistry showed characterization of 2 distinct coexisting malignant cell populations, which helped to select treatment $[2,3]$.

We report herein a case of CLL with concurrent onset of AML with an atypical phenotype revealed by autopsy. Concurrent onset of CLL and AML is rare, and to the best of our knowledge, no autopsy case has been reported. Notably, the diagnosis of AML was difficult during the patient's lifetime because of the atypical phenotype of AML. However, autopsy revealed that the patient's bone marrow, liver, and spleen were filled with large-sized blastic abnormal cells which had characteristic of AML.

\section{Case Report}

A 69-year-old man was referred to our hospital with severe anemia and thrombocytopenia. He was previously healthy and had not received any medication. Laboratory data are shown in Table 1. Splenomegaly was also found on computed tomography (Fig. 1a).

Table 1. Laboratory data and findings of bone marrow aspiration on the admission day

\begin{tabular}{|c|c|c|}
\hline $\mathrm{CBC}$ and coagulation test & Biochemistry & BMA findings and tumor marker \\
\hline WBC $4,240 / \mu \mathrm{L}$ & $\mathrm{TP} 6.9 \mathrm{~g} / \mathrm{dL}$ & NCC $33,000 / \mu \mathrm{L}$ \\
\hline Band 1\% & Alb $4.8 \mathrm{~g} / \mathrm{dL}$ & Megakaryocyte $12 / \mu \mathrm{L}$ \\
\hline Neu $54 \%$ & T.Bil $0.6 \mathrm{mg} / \mathrm{dL}$ & Small lymphocyte $34.8 \%$, CD5+, CD20+, CD23+, \\
\hline Mo 4\% & AST $24 \mathrm{U} / \mathrm{L}$ & light chain $\kappa+$ \\
\hline Lymph $41 \%$ & ALT $18 \mathrm{U} / \mathrm{L}$ & \\
\hline $\mathrm{RBC} 246 \times 10^{6} / \mu \mathrm{L}$ & LDH $282 \mathrm{U} / \mathrm{L}$ & Blastic abnormal cell 21.4\%, CD4+, CD38+, \\
\hline MCV $87.0 \mathrm{fL}$ & $\gamma$-GTP $42 \mathrm{U} / \mathrm{L}$ & CD3-, CD20-, CD5-, CD23-, CD13-, CD34-, \\
\hline $\mathrm{Hb} 7.4 \mathrm{~g} / \mathrm{dL}$ & UA $5.7 \mathrm{mg} / \mathrm{dL}$ & CD117-, MPO-, TdT- \\
\hline Reti $0.24 \%$ & Cre $0.99 \mathrm{mg} / \mathrm{dL}$ & Chromosome analysis: 46, XY, add (1) (p36.1), \\
\hline Plt $1.1 \times 10^{4} / \mu \mathrm{L}$ & BUN 13 mg/dL & $\operatorname{del} 1(1)(p ?),-5,-7,-8,-10,-12,-13,-14$ \\
\hline APTT $27.6 \mathrm{~s}$ & $\mathrm{Na} 141 \mathrm{mmol} / \mathrm{L}$ & -16 , add (19) (p13), -21, +8mar [4], 46, XY [16] \\
\hline PT-INR 76\% & $\mathrm{K} 4.2 \mathrm{mmol} / \mathrm{L}$ & Tumor marker: \\
\hline Fib $255 \mathrm{mg} / \mathrm{dL}$ & $\mathrm{Cl} 107 \mathrm{mmol} / \mathrm{L}$ & sIL-2R 625 U/mL \\
\hline D-D $0.7 \mu \mathrm{g} / \mathrm{mL}$ & Ca 9.3 mg/dL & 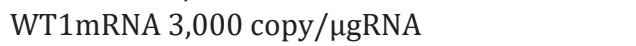 \\
\hline $\mathrm{FDP}<2.5 \mu \mathrm{g} / \mathrm{mL}$ & IP 3.7 mg/dL & \\
\hline
\end{tabular}

CBC, complete blood count; WBC, white blood cell, Band: band neutrophil; Neu, neutrophil; Mo, mononuclear cell; Lymph, lymphocyte; RBC, red blood cell; MCV, mean corpuscular volume; Hb, hemoglobin; Reti, reticulocyte; Plt, platelet; APTT, activated partial thromboplastin time; PT-INR, prothrombin time international normalized ratio; Fib, fibrinogen; D-D, d-dimer; FDP, fibrin and fibrinogen degradation products; TP, total protein; Alb, albumin; T. Bil, total bilirubin; AST, aspartate aminotransferase; ALT, alanine aminotransferase; LDH, lactate dehydrogenase; $\gamma$-GTP, $\gamma$-glutamyl transpeptidase; UA, uric acid; Cre, creatinine; BUN, blood urea nitrogen; $\mathrm{Na}$, sodium; K, potassium; $\mathrm{Cl}$, chlorine; $\mathrm{Ca}$, calcium; IP, inorganic phosphorus; $\mathrm{BMA}$, bone marrow aspiration; NCC, nucleated cell count; CD, cluster of differentiation; MPO, myeloperoxidase; TdT, terminal deoxynucleotidyl transferase; FISH, fluorescence in situ hybridization; sIL-2R, soluble IL-2 receptor; WT1mRNA, WT1 messenger ribonucleic acid. 

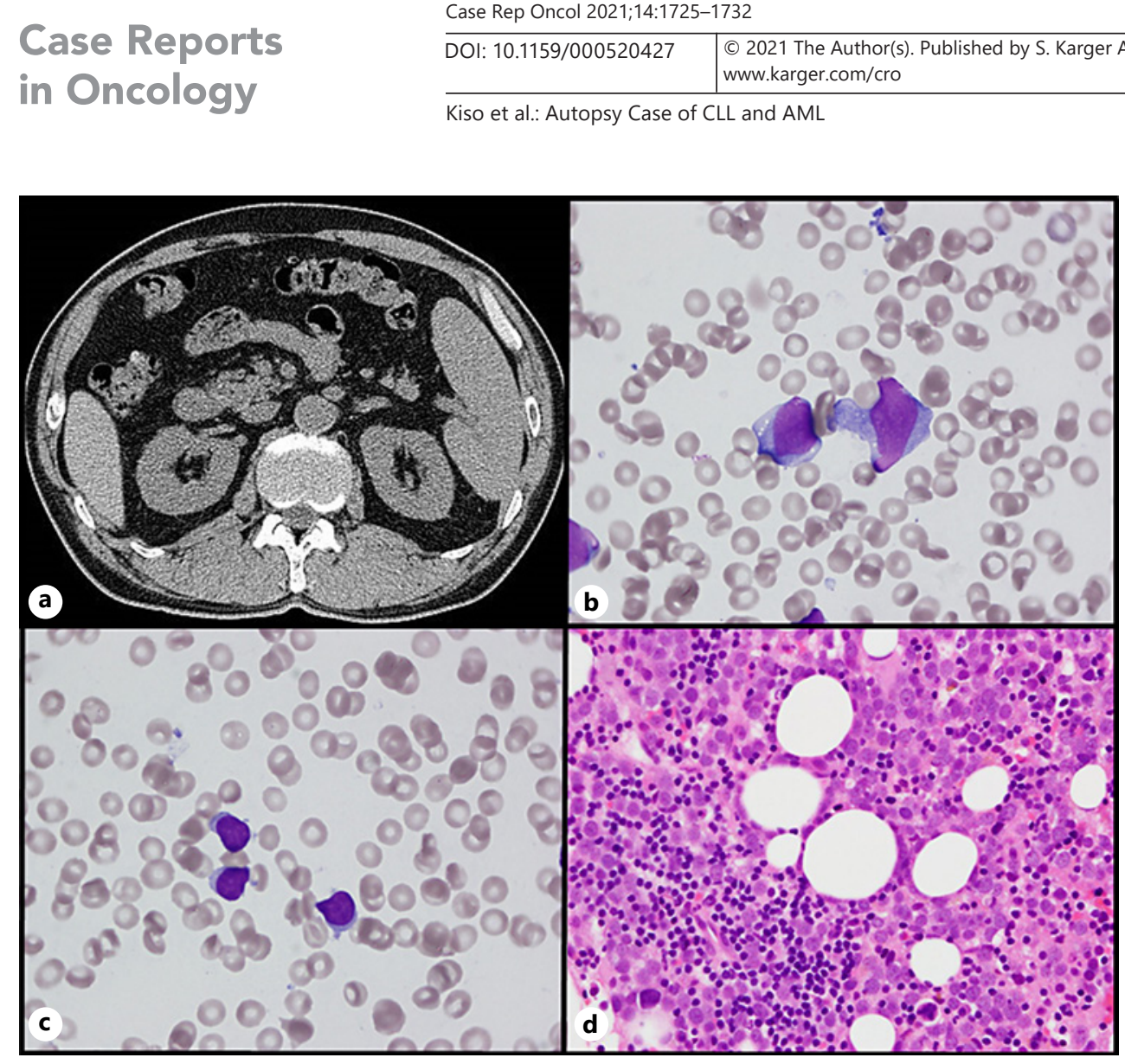

Fig. 1. a Abdominal computed tomography images obtained on the day of admission showed splenomegaly. b The abnormal blastic cell in the bone marrow aspiration smear $(\times 1,000)$. c Small lymphocytes in the bone marrow aspiration smear $(\times 1,000)$. d Pathological image of the bone marrow clot $(\times 400)$.

Bone marrow aspiration (BMA) showed $21.4 \%$ of abnormal blastic cells and small lymphocyte populations (Fig. 1b, c). Flow cytometry revealed that the blastic cells did not express any lineage markers, except for CD4 and CD38. Meanwhile, small lymphocytes expressed CD5, CD20, CD23, and light chain-kappa. Immunohistochemical staining of the bone marrow clot revealed almost similar findings to those of flow cytometry, that is, infiltration of abnormal blastic cells with small lymphocytes to the bone marrow (Fig. 1d). Chromosome analysis showed complex karyotype including -5 and -7 abnormalities. The laboratory data and BMA findings are summarized in Table 1. Based on these findings, we diagnosed the small lymphocyte as CLL with Rai stage IV and Binet stage C, but we could not identify the origin of the abnormal blastic cells. Finally, we considered the abnormal blastic cells to be derived from CLL, such as Richter syndrome, which is an aggressive B-cell lymphoma transformed by CLL. The patient was started on bendamustine and rituximab (BR) treatment for CLL. However, he developed splenomegaly, and his cytopenia did not ameliorate, indicating treatment failure. We decided to start venetoclax as the second-line therapy for CLL, but it was also discontinued due to complications of tumor lysis syndrome. To evaluate the therapeutic effect of venetoclax, BMA was performed again and showed $11.8 \%$ of abnormal blastic cells with no small lymphocyte population, which seemed to be a CLL clone. However, the splenomegaly progressed, and 1-2\% of abnormal blastic cells appeared in the peripheral blood. Finally, he was given palliative care because of his poor general condition and his living will, and he died 84 days after admission. We performed an autopsy with the consent of his family.

Macroscopic findings of the autopsy revealed prominent splenomegaly and hepatomegaly. In microscopy, the patient's bone marrow, spleen, and liver were filled with large-sized abnormal 


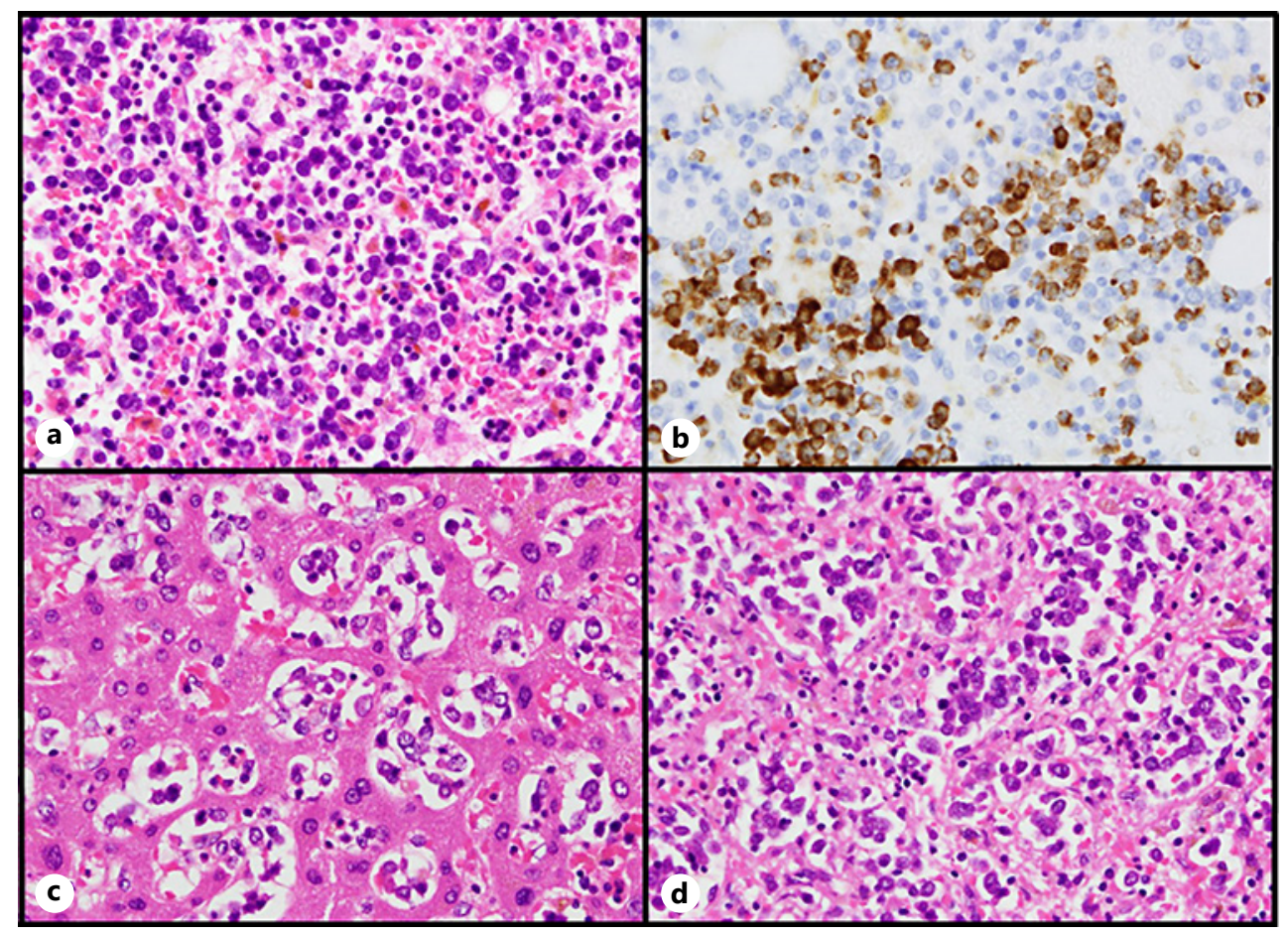

Fig. 2. Autopsy images revealed that the bone marrow, liver, and spleen were filled with blastic abnormal cells. a HE stain of the bone marrow. b MPO stain of the bone marrow. c HE stain of the liver. d HE stain of the spleen $(\times 400)$. HE, hematoxylin-eosin; MPO, myeloperoxidase.

blastic cells. These abnormal blastic cells comprised 70\% nucleated cells in the bone marrow. Almost all the spleen was infiltrated by the abnormal blastic cells, and the border between white pulp and red pulp disappeared. Images of the autopsy specimen are shown in Figure 2. The abnormal blastic cells stained positively for CD4 and partially positive for MPO; negative for CD3, CD5, CD20, CD23, CD34, CD56, and c-kit; and showed p53 overexpression. Findings from flow cytometry and immunohistochemical staining of the abnormal blastic cells are summarized in Table 2. Increasing polymerase chain reaction (PCR) of WT1 mRNA suggested complications of myeloid hematologic malignancy (Table 1). Considering the partial positivity of MPO in autopsy specimens and these findings, we concluded that the abnormal blastic cell was a myeloblast and finally diagnosed the patient with AML with liver and spleen involvement. There was no CLL component. Based on these findings, the major cause of death was the progression of AML. We told the result of autopsy to the family and obtained written informed consent to publish the case from the family.

\section{Discussion}

In this case, the patient suffered from the rare combination of synchronous hematological malignancy: untreated CLL and AML. Because of the rarity and atypical phenotype, we could not diagnose AML until the autopsy proved the myeloblast in the bone marrow, liver, and spleen. Although second malignant neoplasms are more common in patients with CLL, the development of AML or MDS in untreated CLL patients is rare [4]. In Japan, Muta et al. [5] reported the first case of AML concurrently occurring with untreated CLL. Ito et al. [6] reported that the development of AML in patients with untreated CLL was associated with a poor 


\section{Case Reports in Oncology}

Table 2. Summary of findings from flow cytometry and immunohistochemical staining of the abnormal blastic cells

\begin{tabular}{l|l}
\hline Case Rep Oncol 2021;14:1725-1732 \\
\hline DOI: 10.1159/000520427 & $\begin{array}{l}\text { @ 2021 The Author(s). Published by S. Karger AG, Basel } \\
\text { www.karger.com/cro }\end{array}$ \\
\hline
\end{tabular}

\begin{tabular}{llll}
\hline Stain & $\begin{array}{l}\text { Pretreatment } \\
\text { flow cytometry }\end{array}$ & Pretreatment IHC & IHC on autopsy \\
\hline CD4 & + & + & + \\
CD38 & + & na & na \\
CD3 & - & - & - \\
CD20 & - & - & - \\
CD5 & - & - & - \\
CD23 & - & - & - \\
CD13 & - & na & na \\
CD34 & - & - & - \\
CD56 & - & - & - \\
CD117/c-kit & - & - & - \\
MP0 & - & - & + (partial) \\
TdT & - & na & na \\
p53 & na & + & Overexpression \\
\hline
\end{tabular}

IHC, immunohistochemistry; CD, cluster of differentiation; na, not available; MPO, myeloperoxidase; TdT, terminal deoxynucleotidyl transferase.

Table 3. Summary of reports about therapy-related MDS/AML after CLL treatment

\begin{tabular}{llllll}
\hline References & $N$ & CLL treatment & $\begin{array}{l}\text { Median } \\
\text { follow-up } \\
\text { period }\end{array}$ & $\begin{array}{l}\text { Incidence of therapy- } \\
\text { related MDS/AML (\%) }\end{array}$ & $\begin{array}{l}\text { Median } \\
\text { survival after } \\
\text { diagnosis }\end{array}$ \\
\hline Morrison et al. [7] & 521 & $\begin{array}{l}\text { Fludarabine alone/ } \\
\text { fludarabine and } \\
\text { chlorambucil }\end{array}$ & 4.2 years & Six patients (1.2) & 3.5 months \\
Carney et al. [8] & 82 & $\begin{array}{l}\text { Fludarabine and } \\
\text { cyclophosphamide with } \\
\text { or without rituximab }\end{array}$ & 41 months & Five patients (6.1) & 11 months \\
Colovic et al. [9] & $210 \begin{array}{l}\text { Fludarabine and } \\
\text { cyclophosphamide }\end{array}$ & 46 months & Four patients (1.9) & 4 months \\
\hline
\end{tabular}

MDS, myelodysplastic syndrome; AML, acute myeloid leukemia; CLL, chronic lymphocytic leukemia.

response to chemotherapy and extremely poor prognosis. To the best of our knowledge, this is the first autopsy case of concurrent onset of CLL and AML, and complications of AML were revealed by autopsy.

On the other hand, there are several reports about therapy-related MDS/AML developed after CLL treatment. As shown in Table 3, fludarabine-containing regimens seemed to be associated with the occurrence of MDS/AML [7-9]. In our case, the patient was previously healthy and had not received any medication including fludarabine.

Most previous studies reported that concurrent-onset CLL and AML are different clones $[5,10,11]$. However, Ito et al. $[6,12,13]$ suggested the possibility of CLL and AML from the same origin because both tumors are related to TP53 alterations and aberrant Wnt signaling. In our case, we added p53 staining of the first BMA smear and PCR of IgH rearrangement in the bone marrow clot specimen for the first BMA and the autopsy specimen of the spleen. The abnormal blastic cells stained positively for p53, while the CLL component, which showed 


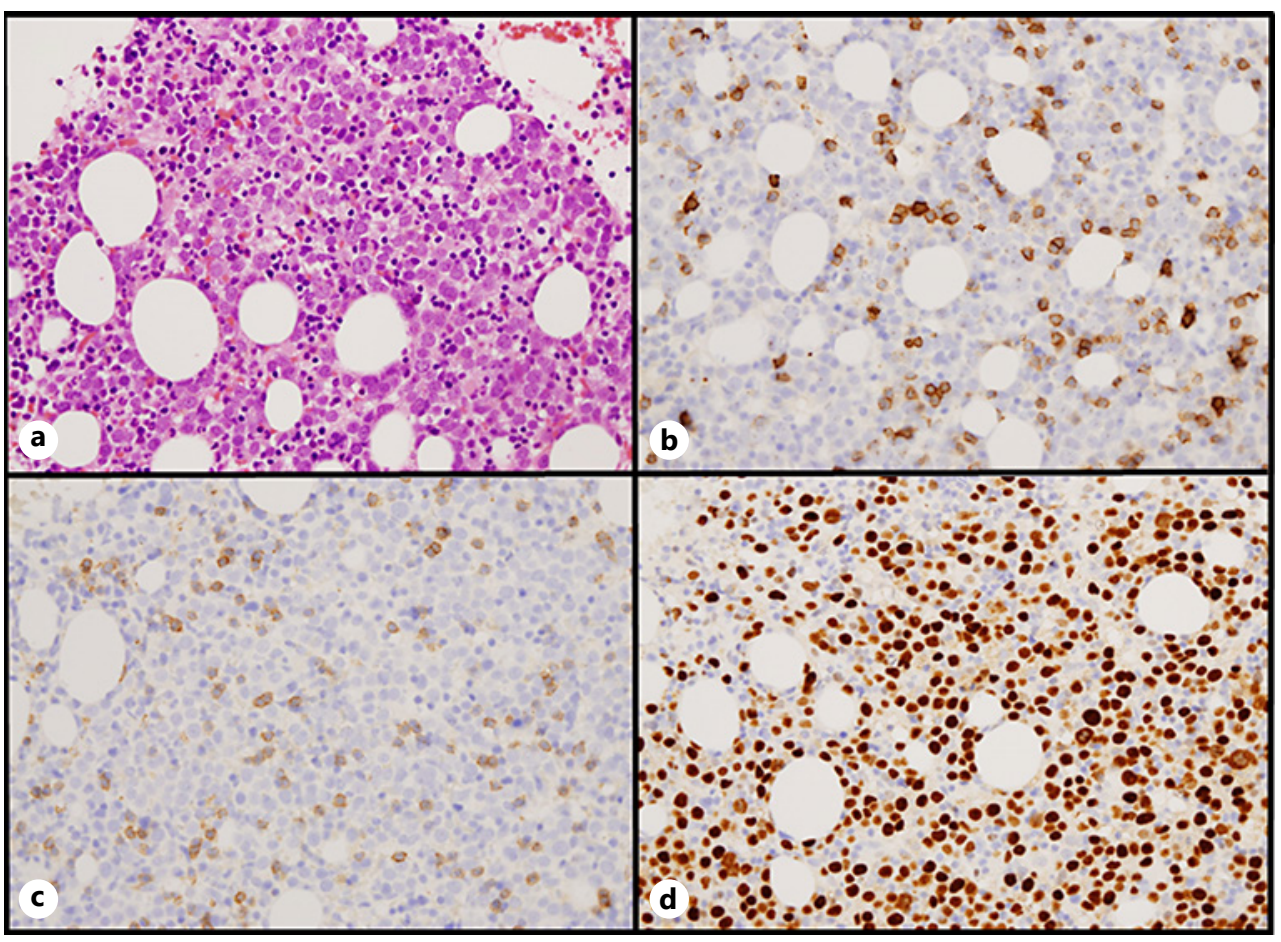

Fig. 3. Images of the HE, CD5, CD23, and added p53 stain of the first bone marrow aspiration smear. The abnormal blastic cells were positive for p53, but the CLL component, which showed CD5 and CD23 double positivity, was negative for p53. a HE stain. b CD5 stain. c CD23 stain. d p53 stain ( $\times 400)$. HE, hematoxylin-eosin; $\mathrm{CD}$, cluster of differentiation.

CD5 and CD23 double positivity, was negative for p53 (Fig. 3). In addition, IgH gene rearrangement was detected in the bone marrow clot specimen in the first BMA but was not detected in PCR of the autopsy specimen of the spleen. Based on these findings, we assumed that CLL and AML were different clones.

We could not identify AML before autopsy because both flow cytometry and immunohistochemical staining did not show typical antigens of AML. In addition, autopsy revealed that myeloblasts filled the bone marrow, liver, and spleen, but there were very few abnormal blastic cells in the peripheral blood during his lifetime. This is quite an atypical distribution for AML, although there have been few case reports [14]. We assumed that this unusual clinical presentation of AML was due to the progression of MDS. In the case of AML with myelodysplasia-related changes, immunophenotyping results are variable due to the heterogeneity of the underlying disease. Decreased expressions of HLA-DR, CD117, CD135, and CD38 are reported to be associated with multilineage dysplasia [15]. Kitagawa et al. [16] reported that p53-positive cells were also positive for the myeloid cell marker, and all of their 7 MDS cases that exhibited p53 expression at the time of initial diagnosis later developed overt leukemia. In our case, the autopsy revealed overexpression of p53 in the bone marrow, liver, and spleen, which helped to suspect progression of MDS to overt leukemia.

We reviewed the diagnosis of CLL because of the bone marrow infiltration of CLL cells, but the origin of the abnormal blastic cells could not be defined before biopsy. We mistook the abnormal blastic cells for cells derived from CLL, similar to Richter syndrome, and the treatment aiming for CLL seemed reasonable at that time, but the autopsy revealed the blastic cells were myeloblasts, and they seemed to be derived from different clones. Thus, BR treatment 
seemed to be effective for CLL, but not for AML. Subsequent venetoclax treatment resulted in the disappearance of CLL clones and reduced the number of myeloblasts. However, the therapeutic effect was still limited. Although venetoclax is a BCL-2 inhibitor and has been reported to be effective in not only CLL but also AML, single-agent venetoclax has been reported to have insufficient antileukemia effect in AML [17].

In conclusion, we experienced a case of concurrent onset of CLL and atypical phenotype AML with liver and spleen involvement revealed by autopsy. The case findings highlight the importance of considering the synchronous complications of AML in CLL patients, particularly in those who show an atypical clinical course.

\section{Acknowledgments}

We would like to thank all the staff at Chugoku Central Hospital of the Japan Mutual Aid Association of Public School Teachers for their contribution to this report.

\section{Statement of Ethics}

Written informed consent has been obtained from the patient's family for publication. The study protocol was approved by the Chugoku Central Hospital Ethics Committee on June $17,2020$.

\section{Conflict of Interest Statement}

The authors declare no potential conflicts of interest regarding the publication of this study.

\section{Funding Sources}

No funding was received for this study.

\section{Author Contributions}

S.K. wrote this manuscript. H.S. managed the clinical practice and authored this case study. T.K. managed and supervised the clinical practice. R.O. and T.T. managed the autopsy and supervised the pathological part of this study. T.I., S.O., N.N., T.M., and N.S. advised on the manuscript. T.K. and M.T. supervised the clinical practice.

\section{Data Availability Statement}

The data during this study are available from the corresponding author on reasonable request. 


\section{References}

1 Foucar K. B cell chronic lymphocytic leukemia (CLL) and prolymphocytic leukemia. Baltimore, MD: Williams and Wilkins; 1991.

2 Wiernik PH. Second neoplasms in patients with chronic lymphocytic leukemia. Curr Treat Options Oncol. 2004;5:215-23.

3 DeFilipp Z, Huynh DV, Fazal S, Sahovic E. Allogeneic stem cell transplantation for acute myeloid leukemia with $\operatorname{del}(7 q)$ following untreated chronic lymphocytic leukemia. Hematol Oncol Stem Cell Ther. 2012;5:165-8.

4 Lai R, Arber DA, Byrnes RK, Chan O, Chang KL. Untreated chronic lymphocytic leukemia concurrent with or followed by acute myelogenous leukemia or myelodysplasic syndrome. A report of five cases and review of the literature. Am J Clin Pathol. 1999;111:373-8.

5 Muta T, Okamura T, Niho Y. Acute myelogenous leukemia concurrent with untreated chronic lymphocytic leukemia. Int J Hematol. 2002;75:187-90.

6 Ito S, Fujiwara S, Mashima K, Umino K, Minakata D, Nakano H, et al. Development of acute myeloid leukemia in patient with untreated chronic lymphocytic leukemia. Ann Hematol. 2017;96:719-24.

7 Morrison VA, Rai KR, Peterson BL, Kolitz JE, Elias L, Appelbaum FR, et al. Therapy-related myeloid leukemias are observed in patients with chronic lymphocytic leukemia after treatment with fludarabine and chlorambucil: results of an intergroup study, cancer and leukemia group B 9011. J Clin Oncol. 2002;20:3878-84.

8 Carney DA, Westerman DA, Tam CS, Milner A, Prince HM, Kenealy M, et al. Therapy-related myelodysplastic syndrome and acute myeloid leukemia following fludarabine combination chemotherapy. Leukemia. 2010; 24:2056-62.

9 Colović M, Suvajdžić N, Janković G, Tomin D, Colović N, Fekete MD, et al. Therapy-related myelodysplastic syndrome and acute myeloid leukemia in patients with chronic lymphocytic leukemia treated with fludarabine and cyclophosphamide. Biomed Pharmacother. 2011;65:319-21.

10 Culligan DJ, Cachia P, Whittaker J, Jacobs A, Padua RA. Clonal lymphocytes are detectable in only some cases of MDS. Br J Haematol. 1992;81:346-52.

11 Mitterbauer G, Schwarzmeier J, Mitterbauer M, Jaeger U, Fritsch G, Schwarzinger I. Myelodysplastic syndrome/ acute leukemia supervening previously untreated chronic B-lymphocytic leukemia: demonstration of the concomitant presence of two different malignant clones by immunoligic and molecular analysis. Ann Haematol. 1997;74:193-7.

12 Stengel A, Kern W, Haferlach T, Meggendorfer M, Fasan A, Haferlach C. The impact of TP53 mutations and TP53 deletions on survival varies between AML, ALL, MDS and CLL: an analysis of 3307 cases. Leukemia. 2017;31: 705-11.

13 Staal FJ, Famili F, Garcia Perez L, Pike-Overzet K. Aberrant Wnt signaling in leukemia. Cancers. 2016; 8:78.

14 Chen WL, Hsu YJ, Tsai WC, Tsao YT. An unrusual case of febrile neutropenia: acute myeloid leukemia presenting as myeloid sarcoma of spleen. J Natl Med Assoc. 2008;100:957-9.

15 Miesner M, Haferlach C, Bacher U, Weiss T, Macijewski K, Kohlmann A, et al. Multilineage dysplasia (MLD) in acute myeloid leukemia (AML) correlates with MDS-related cytogenetic abnormalities and prior history of MDS or MDS/MPN but has no independent prognostic relevance: a comparison of 408 cases classified as "AML not otherwise specified" (AML-NOS) or "AML with myelodysplasia-related changes" (AML-MRC). Blood. 2010; 116:2742-51.

16 Kitagawa M, Yoshida S, Kuwata T, Tanizawa T, Kamiyama R. p53 expression in myeloid cells of myelodysplastic syndromes. Association with evolution of overt leukemia. Am J Pathol. 1994;145:338-44.

17 Guerra VA, Dinardo C, Konopleva M. Venetoclax-based therapies for acute myeloid leukemia. Best Pract Res Clin Haematol. 2019;32:145-53. 